JKM (Jurnal Kebidanan Malahayati),Vol 7,No.3.Juli 2021,

ISSN (Print) 2476-8944 ISSN (Online) 2579-762X, Hal 593-598

\title{
TINGKAT PENGETAHUAN IBU HAMIL TERHADAP KUNJUNGAN PEMERIKSAAN ANTENATAL CARE
}

\author{
Desi Hariani', Elvina Indah Syafriani² \\ 1,2Program Studi DIII Kebidanan STIK Siti Khadijah Palembang \\ Email : desibidan84@gmail.com
}

\section{ABSTRACT LEVEL OF KNOWLEDGE OF PREGNANT WOMEN ON ANTENATAL CARE VISITS}

Background Antenatal care is important to ensure that natural processes continue to run normally during pregnancy. The fetus in the womb develops along with the gestational age, so if it is not properly monitored it can cause problems, both in pregnancy, childbirth and the puerperium, it can also result in the death of the mother and baby. Based on data from the Kenten Laut Banyuasin Health Center in 2020, the number of pregnant women who made ANC visits was 87 people.

The purpose of this study was to determine the relationship between the level of knowledge of pregnant women and antenatal care examination visits.

Methods This research method used a quantitative descriptive surver with a cross sectional approach and univariate and bivariate analysis using the chi square test. The population of this study were some pregnant women who visited were taken randomly at the Kenten Laut Banyuasin Health Center in 2020, with a total population of 32 people.

The results of this study indicate that there is a relationship between the level of knowledge of pregnant women about ANC with ANC visits at the Kenten Laut Banyuasin Health Center in 2020 with a value of 0.008 $<0.005$. Therefore it is important for pregnant women to carry out prenatal examinations from the beginning so that it will be easier to know the baby's development and can detect signs of danger early to prevent complications early.

Conclusion There is a relationship between the level of knowledge of pregnant women about ANC with ANC visits at the Kenten Laut Banyuasin Health Center in 2020 with a value of $0.008<0.005$.

Suggestions are expected for future researchers to conduct research on antenatal care with more interesting variables so that they can be studied more about antenatal care examinations and can be reviewed about the problems that exist in pregnant women so that pregnant women are healthier and of higher quality.

Keywords : antenatal care visits,knowledge of pregnant women, maternal mortality

\section{ABSTRAK}

Latar Belakang Asuhan antenatal care penting untuk menjamin agar proses alamiah tetap berjalan normal selama kehamilan. Janin dalam kandungan berkembang seiring dengan besar usia kehamilan, maka apabila tidak dilakukan pengawasan yang tepat bisa menyebabkan masalah, baik dalam kehamilan, persalinan dan nifasnya, bisa juga mengakibatkan kematian ibu dan bayi. Berdasarkan data Puskesmas Kenten Laut Banyuasin Tahun 2020 jumlah ibu hamil yang melakukan Kunjungan ANC sebanyak 87 orang.

Tujuan penelitian ini untuk mengetahui hubungan tingkat pengetahuan ibu hamil terhadap kunjungan pemeriksaan antenatal care.

Metode Penelitian ini menggunakan Surver Deskriptif Kuantitatif dengan pendekatan Cross Sectional dan analisa univariat dan bivariat menggunakan uji chi square, Populasi penelitian ini adalah sebagian ibu hamil yang melakukan kunjungan diambil secara random sampling di Puskesmas Kenten Laut Banyuasin Tahun 2020, jumlah total populasi 32 orang.

Hasil penelitian ini menjunjukkan bahwa ada hubungan tingkat pengetahuan ibu hamil tentang ANC dengan kunjungan ANC di Puskesmas Kenten Laut Banyuasin Tahun 2020 dengan $p$ value 0,008 0,005. Maka dari itu penting bagi ibu hamil untuk melakukan pemeriksaan kehamilan dari awal sehingga akan lebih mudah mengetahui perkembangan bayi dan dapat mendeteksi secara dini tanda-tanda bahaya untuk mencegah komplikasi secara dini.

Kesimpulan Ada hubungan tingkat pengetahuan ibu hamil tentang ANC dengan kunjungan ANC di Puskesmas Kenten Laut Banyuasin Tahun 2020 dengan $p$ value 0,008 $<0,005$. 
Saran diharapkan untuk peneliti selanjutnya untuk melakukan penelitian tentang antenatal care dengan variabel yang lebih menarik sehingga bisa dikaji lebih banyak lagi tentang pemeriksaan antenatal care dan bisa dikaji ulang tentang permasalahan yang ada pada ibu hamil supaya ibu hamil lebih sehat dan berkualitas

Kata Kunci : : Kunjungan Antenatal care, Pengetahuan ibu hamil, AKI

\section{PENDAHULUAN}

Asuhan antenatal penting untuk menjamin agar proses alamiah tetap berjalan normal selama kehamilan. Kehamilan merupakan proses alamiah yang akan dialami oleh setiap wanita. Lama kehamilan sampai aterm adalah 280 sampai 300 hari atau 39-40 minggu, sehingga sampai masa tersebut ibu hamil memerlukan pengawasan yang tepat (Manuaba, 2006). Janin dalam kandungan berkembang seiring dengan besar usia kehamilan, maka apabila tidak dilakukan pengawasan yang tepat bisa menyebabkan masalah, baik dalam kehamilan, persalinan dan nifasnya, bisa juga mengakibatkan kematian ibu dan bayi.

Menurut Worlt Health Organization (WHO,2017), kematian ibu hamil masih merupakan salah satu masalah kesehatan reproduksi yang sangat penting. Lebih dari 135 jiwa wanita melahirkan setiap tahun, namun sebagian besar ibu hamil tidak memeriksakan kehamilannya ketenaga kesehatan. Meskipun demikian, sebagian besar ibu hamil memeriksa kan diri setidaknya satu kali selama proses kehamilan, namun hanya setengah dari ibu hamil yang memeriksakan diri minimal 4 kali selama proses kehamilan. Setiap kehamilan dapat menimbulkan resiko kematian ibu. Kematian maternal juga merupakan salah satu masalah terbesar di negara-negara berkembang. Rasio kematian ibu hamil di negara berkembang adalah 230 per 100.000 kelahiran sedangkan di negara maju, rasio kematian ibu hamil adalah 16 per 100.000 kelahiran. Dari 800 kematian ibu hamil setiap hari, 500 berada di sub Sahara Afrika, $190 \mathrm{di}$ Asia Selatan dan 6 di negara-negara berpenghasilan tinggi.

Cakupan pelayanan antenatal care dapat dipantau melalui kunjungan ibu hamil KI untuk mengetahui jangkauan pelayanan antenatal, serta kemampuan program dalam menggerakkan masyarakat dan cakupan K4 yang merupakan cakupan ibu hamil yang telah memperoleh pelayanan antenatal sesuai dengan standar. Upaya ini dapat memberikan hasil yang maksimal bila didukung dengan peningkatan pelayanan antenatal care, yaitu dengan 3 memberikan pelayanan sekurang-kurangnya enam kali selama masa kehamilan. Kunjungan Antenatal Care (ANC) minimal dilakukan satu kali pada trimester pertama
(K1), dua kali pada trimester kedua (K2), dan tiga kali pada trimester ketiga (K3 dan K4) (Kemenkes $\mathrm{RI}, 2017)$.

Dari data profil kesehatan Provinsi Sumatera Selatan tahun 2015, cakupan kunjungan KI mencapai $98,0 \%$. Dan kunjungan K4 mencapai 93,53\%. K1 dan K4 di Provinsi Sumatera Selatan berkisar antara 0,9\%-6,34\%. Walaupun selisih K1 dengan K4 masih dibawah 10\%, namun tetap harus menjadi perhatian bahwa masih ada ibu hamil yang pemeriksaan kehamilannya belum mencapai 4 kali selama kehamilannya.

Menurut Lawrence Green, faktor-faktor yang memengaruhi Kunjungan pemeriksaan kehamilan ada 3 yaitu : faktor predisposisi (pengetahuan, sikap, kepercayaan, tradisi, keyakinan, nilai dan motivasi), faktor pendukung (ketersediaan fasilitasfasilitas atau sarana-sarana kesehatan), dan faktor pendorong (sikap dan perilaku petugas kesehatan). Kurangnya pemanfaatan ANC oleh ibu hamil ini berhubungan dengan faktor-faktor predisposisi yang terwujud dalam pendidikan, pengetahuan, jumlah anak, pendidikan suami, sikap umur, pekerjaan, pendapatan, biaya ANC (Notoatmodjo,2016).

Berdasarkan Profil Kesehatan kota Palembang tahun 2015, cakupan pelayanan ibu hamil untuk kunjungan pertama kali (KI) sebesar $99,84 \%$ dan kunjungan ke empat (K4) sebesar 96,64\% ibu hamil. Sedangkan pada tahun 2015 kunjungan K1 sebesar 99.93\% dan kunjungan K4 sebesar $97,41 \%$ ibu hamil.

Tujuan pemeriksaan ANC yaitu untuk mendeteksi kelainan-kelainan yang mungkin ada atau akan timbul pada kehamilan tersebut. Melalui deteksi dini, kelainan dapat dicegah dan diatasi dengan segera sebelum berpengaruh tidak baik terhadap kehamilan. Manfaat memeriksakan kehamilan sangat besar, maka dianjurkan untuk melakukan kunjungan ANC semenjak wanita merasa hamil (Padila, 2014).

Berdasarkan hasil survey di Puskesmas Kenten Laut Banyuasin tahun 2019 adalah ibu hamil yang melakukan kunjungan ANC KI-K4 didapatkan bahwa sebanyak 746 kunjungan. Dengan kunjungan KI 221 kunjungan (29,6\%), dengan kunjungan K4 525 kunjungan $(70,3 \%)$ dengan jumlah sasaran ibu hamil 9.445( 92,46). Pada tahun 2017 melakukan kunjungan ANC KI-K4 
didapatkan bahwa sebanyak 696 kunjungan. Dengan kunjungan KI 236 kunjungan (33,9\%), dengan kunjungan K4 460 kunjungan (66\%)dengan jumlah sasaran ibu hamil 9.784 jiwa. Pada tahun 2018 melakukan kunjungan ANC KI-K4 didapatkan bahwa sebanyak 681 kunjungan. Dengan kunjungan $\mathrm{KI} 218$ kunjungan (32,0\%), dengan kunjungan K4 463 kunjungan (67,9\%). Dan pada januari hingga mei 2017 melakukan kunjungan ANC KI-K4 didapatkan bahwa sebanyak 215 kunjungan. Dengan kunjungan KI 89 kunjungan $(41,3 \%)$, dengan kunjungan K4 126 kunjungan (58\%), selain itu jumlah AKI Di Puskesmas Kenten Laut pada tahun 2018 yaitu 3 per 100.000 kelahiran hidup dan AKB 2 Per 1000 Kelahiran hidup Dari latar belakang diatas penulis tertarik untuk mengambil kasus yang berjudul " Tingkat Pengetahuan lbu Hamil Terhadap Kunjungan Pemeriksaan Antenatal Care Di Puskesmas Kenten Laut Banyuasin Tahun 2020."

Tujuan penelitian untuk mengetahui ada hubungan antara tingkat pengetahuan ibu hamilterhadap kunjungan Antenatal care di Puskesmas Kentel Laut Banyuasin

\section{METODOLOGI PENELITIAN}

Penelitian ini dilakukan dengan dua cara yaitu untuk variabel tingkat pengetahuan ibu hamil dengan menyebarkan kuesioner dan untuk kunjungan Antenatal caredan untuk variabel kunjungan pemeriksaan dilihat dari bukti buku KIA ibu.Jenis penelitian ini menggunakan Deskriftif kuantitatif dengan populasi penelitian semua ibu hamil yang melakukan kunjungan pemeriksaan antenatal care.Variabel pengetahuan dikelompokan menjadi dua kategori Kode $1=$ Tidak Baik (Jika ibu mampu menjawab pertanyaan $<75 \%$ ), Kode $2=$ Baik (Jika ibu mampu menjawab pertanyaan $\geq 75 \%$ ), sedangkan untuk variabel kunjungan di kelompokan menjadi dua Kedua kunjungan ANC Kode 1 = Patuh (Jika pada TM 1 dilakukan <1x, TM II $<1 \mathrm{x}$, TM III $<2$ kali), Kode 2 = Tidak patuh (Jika pada TM I dilakukan $\geq 1 \mathrm{x}$, TM $\| \geq 1 \mathrm{x}$, TM $\| \mathrm{II} \geq 2$ kali).Analisis yang digunakan adalah univariat dan bivariat. Uji statistiuk yang digunakan yakni uji Chi Square

\section{HASIL DAN PEMBAHASAN \\ Analisis Univariat}

Analisis Univariat ini dilakukan untuk mengetahui distribusi frekuensi dan persentase dari variabel independen yaitu tingkat pengetahuan dan variabel dependen yaitu kunjungan ANC.

\section{Tingkat Pengetahuan}

Dalam penelitian ini variabel tingkat pengetahuan dibagi dalam 2 kategori yaitu Baik, apabila responden memiliki skor pengetahuan $\geq 75$ $\%$ dan kategori Tidak Baik, apabila responden memiliki skor pengetahuan $<75 \%$.

Tabel 1.

Distribusi Frekuensi dan Presentase Tingkat Pengetahuan Ibu Hamil Tentang Antenatal Care (ANC) di Puskesmas Kenten Laut Banyuasin Tahun 2020

\begin{tabular}{|c|c|c|}
\hline Tingkat Pengetahuan & $\mathbf{n}$ & $\%$ \\
\hline Baik & 10 & $31,3 \%$ \\
\hline Tidak Baik & 22 & $68,8 \%$ \\
\hline Total & 32 & $100 \%$ \\
\hline
\end{tabular}

Daritabel 1dapat diketahui bahwa dari 32 responden ibu hamil, responden dengan tingkat pengetahuan baik berjumlah $10(31,3 \%)$ lebih sedikit dari pada responden dengan tingkat pengetahuan tidak baik yaitu berjumlah $22(68,8)$.

\section{Kunjungan ANC}

Dalam penelitian ini variabel tingkat pengetahuan dibagi dalam 2 kategori yaitu Berkualitas, apabila kunjungan ANC $>3$ kali kunjungan dan kategori Tidak Berkualitas, apabila kunjungan ANC $\leq 3$ kali kunjungan.

Tabel 2.

Distribusi Frekuensi dan PresentaseKunjungan Antenatal Care (ANC) di Puskesmas Kenten Laut Banyuasin Tahun 2020

\begin{tabular}{|c|c|c|}
\hline Kunjungan ANC & $\mathbf{N}$ & $\%$ \\
\hline Patuh & 14 & $43,8 \%$ \\
\hline Tidak Patuh & 18 & $56,3 \%$ \\
\hline Total & 32 & $100 \%$ \\
\hline
\end{tabular}

Dari tabel 2 dapat diketahui bahwa dari 32 responden ibu hamil, responden dengan kunjungan ANC yang berkualitas berjumlah $14(43,8 \%)$ lebih sedikit dari pada responden dengan kunjungan ANC yang tidak berkualitas berjumlah18 (56,3\%).

Analisis Bivariat ini dilakukan untuk mengetahui adanya hubungan antara variabel independen yaitu tingkat pengetahuan dengan varibel dependen yaitu kunjungan ANC. Uji statistik yang digunakan adalah Chi-Square dengan batas kemaknaan, bila pvalue $<0,05$ artinya ada hubungan yang bermakna (signifikan) dan bila pvalue $\geq 0,05$ artinya tidak ada hubungan yang bermakna (signifikan). Hubungan Tingkat Pengetahuan lbu Hamil tentang Kunjungan ANC Dengan Kunjungan ANC di Puskesmas Kenten Laut Banyuasin Tahun 2020. 
Tabel 3.

Hubungan Tingkat Pengetahuan IbuHamil tentang Antenatal Care (ANC) Dengan Kunjungan ANC di Puskesmas Kenten Laut Banyuasin Tahun 2020

\begin{tabular}{cccccccc}
\hline \multirow{3}{*}{ Tingkat Pengetahuan } & \multicolumn{4}{c}{ Kunjungan ANC } & \multirow{2}{*}{ Total } & \multirow{2}{*}{ P value } \\
\cline { 2 - 6 } & \multicolumn{2}{c}{ Tidak Patuh } & \multicolumn{2}{c}{ Patuh } & \multicolumn{2}{c}{} & \\
\cline { 2 - 6 } & $\mathrm{N}$ & $\%$ & $\mathrm{~N}$ & $\%$ & $\mathrm{n}$ & $\%$ & \\
\hline Tidak Baik & 16 & $72,7 \%$ & 6 & $27,3 \%$ & 22 & $100 \%$ & \multirow{2}{*}{0,008} \\
Baik & 2 & $20,0 \%$ & 8 & $80,0 \%$ & 10 & $100 \%$ & \\
\hline Jumlah & 18 & $56,2 \%$ & 14 & $43,8 \%$ & 32 & $100 \%$ & \\
\hline
\end{tabular}

Berdasarkan tabel 3 didapatkan bahwa dari 22 responden dengan tingkat pengetahuan tidak baik dan melakukan kunjungan ANC tidak patuh berjumlah $16(72,7 \%)$ lebih banyak dibandingkan 10 responden dengan tingkat pengetahuan baik dan kunjungan ANC yang tidak patuh berjumlah 2 $(20 \%)$. Hasil uji Chi-Squarediperoleh $p$ value $=$ $0,008<0,05$ maka dapat disimpulkan bahwa ada hubungan yang signifikan antara tingkat pengetahuan ibu hamil dengan kunjungan ANC.

\section{PEMBAHASAN}

\section{Tingkat Pengetahuan}

Hasil penelitian diketahui bahwa dari 32 responden ibu hamil, responden dengan tingkat pengetahuan baik berjumlah $10(31,3 \%)$ lebih sedikit dari pada responden dengan tingkat pengetahuan tidak baik yaitu berjumlah $22(68,8)$. Hal ini disebabkan karena rasa keingintahuan ibu hamil sangat sedikit.

Pemeriksaan kehamilan adalah serangkaian pemeriksaan yang dilakukan secara berkala dari awal kehamilan hingga proses persalinan untuk memonitor kesehatan ibu dan janin agar tercapai kehamilan yang optimal. Pemeriksaan kehamilan sangat disarankan bagi para ibu hamil agar kesehatan ibu dan janin terus terpantau (Hutahean, 2013). Tujuan antenatal care diantaranya untuk menjaga agar ibu sehat selama masa kehamilan, persalinan, dan nifas serta mengusahakan bayi yang dilahirkan sehat, memantau kemungkinan adanya resiko-resiko kehamilan, dan merencanakan penatalaksanaan yang optimal terhadap kehamilan resiko tinggi serta menurunkan morbiditas dan mortalitas ibu dan perinatal (Prawirohardjo, 2012).

Sejalan dengan penelitian Sari (2015) tentang pengetahuan tentang tujuan antenatal care yang baik sangat menentukan perkembangan kesehatan kehamilannya dan kesehatan ibu itu sendiri. Pengetahuan yang baik tentang antenatal care bagi ibu hamil bermanfaat sebagai kegiatan yang dilakukan untuk mendeteksi kemungkinan komplikasi yang dialami, mempersiapkan kelahiran, serta memberikan pendidikan kesehatan sertakhusus seputar kehamilan.

Sejalan dengan penelitian Notoatmodjo (2012) tentang pengetahuan seorang ibu tentang kehamilan sangat diperlukan untuk menjalani proses kehamilannya. Banyak sumber informasi yang dapat diperoleh ibu untuk meningkatkan pengetahuan tentang kehamilannya, seperti dari petugas kesehatan maupun media masa, media elektronik, dan media cetak.

Sejalan dengan penelitian suryandari (2013) tentang tingkat pengetahuan dapat diketahui bahwa sebagian besar responden yang berpengetahuannya cukup yaitu sebanyak 22 responden $(73,3 \%)$ sedangkan 5 responden $(26,7 \%)$.

Berdasarkan hasil, teori dan penelitian terkait maka peneliti berpendapat bahwa tingkat pengetahuan ibu hamil tidak baik karena tingkat rasa keingin tahuannya rendah, pendidikan ibu kurang baik, faktor umur, ekonomi, sosial budaya, serta banyak ibu hamil yang menganggap kehamilannya baik-baik saja. Kurangnya tingkat pengetahuan ibu hamil tentang ANC dapat berdampak buruk terhadap ibu dan janin karena ibu hamil tidak tahu apa yang dibutuhkan untuk bayi dan untuk ibu hamil itu sendiri, dan kurang mengetahui tanda-tanda bahaya kehamilan.

\section{Kunjungan ANC}

Hasil penelitian diketahui bahwa dari 32 responden ibu hamil, responden dengan kunjungan ANC yang patuh berjumlah $14(43,8 \%)$ lebih sedikit dari pada responden dengan kunjungan ANC yang tidak patuh berjumlah 18 (56,3\%). Hal ini disebabkan karena kualitas kunjungan ibu hamil yang lengkap contohnya seperti ibu hamil datang pada trimester IV saja.

Kunjungan antenatal untuk pemantauan dan pengawasan kesejahteraan ibu dan anak minimal empat kali selama kehamilan dalam waktu sebagai berikut : sampai dengan kehamilan trimester pertama (<14 minggu) satu kali kunjungan, dan kehamilan trimester kedua (14-28 minggu) satu kali 


\section{JKM (Jurnal Kebidanan Malahayati),Vol 7,No.3.Juli 2021, ISSN (Print) 2476-8944 ISSN (Online) 2579-762X, Hal 593-598}

kunjungan dan kehamilan trimester ketiga (28-36 minggu dan sesudah minggu ke-36) dua kali kunjungan (Saifuddin, 2005).

Sejalan dengan penelitian Suryandari (2013) tentang kunjungan ANC dapat diketahui bahwa sebagian besar kunjungan ANC sesuai standar yaitu sebanyak 26 responden $(86,7 \%)$, dan kunjungan ANC yang tidak sesuai standar yaitu sebanyak 4 responden $(13,3 \%)$.

Berdasarkan hasil, teori dan penelitian terkait maka peneliti berpendapat bahwa kurangnya pengetahuan ibu hamil tentang kunjungan kehamilan dapat meningkatkan kejadian resiko tinggi pada kehamilan. Salah satu peran bidan dalam masyarakat adalah meningkatkan pengetahuan kesehatan masyarakat khususnya tentang ANC. Pengawasan Antenatal Care (ANC) merupakan cara yang mudah untuk mendeteksi kesehatan ibu hamil apakah ada masalah pada kehamilannya atau dalam kesehatan ibu hamil itu sendiri.

\section{Hubungan Tingkat Pengetahuan lbu Hamil tentang Antenatal Care (ANC) Dengan Kunjungan ANC di Puskesmas Kenten Laut Banyuasin Tahun 2020}

Berdasarkan hasil penelitian, bahwa dari 22 responden dengan tingkat pengetahuan tidak baik dan melakukan kunjungan ANC tidak patuh berjumlah $16(72,7 \%)$ lebih banyak dibandingkan 10 responden dengan tingkat pengetahuan baik dan kunjungan ANC yang tidak patuh berjumlah 2 (20\%). Ibu yang tingkat pengetahuannya tidak baik lebih cenderung tidak melakukan kunjungan ANC. Hal ini disebabkan oleh rasa keingin tahuan ibu sangat rendah.

Hasil uji Chi-Square diperoleh $p$ value $=$ $0,008<0,05$ maka dapat disimpulkan bahwa ada hubungan yang signifikan antara tingkat pengetahuan ibu hamil dengan kunjungan ANC.

Salah satu indikasi pemanfaatan pelayanan kesehatan adalah keaktifan kedatangan masyarakat ke pusat pelayanan tersebut yang dalam hal ini spesifikasi kepada pemanfaatan pelayanan ANC. Pemanfaatan pelayanan ANC oleh sejumlah ibu hamil di Indonesia belum sepenuhnya sesuai dengan pedoman yang ditetapkan. Hal ini cenderung menyulitkan tenaga kesehatan dalam melakukan pembinaan pemeliharaan kesehatan ibu hamil secara teratur dan menyeluruh, termasuk deteksi dini terhadap faktor resikokehamilan yang segera ditangani (Peranginangin, 2006).

Kunjungan antenatal untuk pemantauan dan pengawasan kesejahteraan ibu dan anak minimal empat kali selama kehamilan dalam waktu sebagai berikut : sampai dengan kehamilan trimester pertama (<14 minggu) satu kali kunjungan, dan kehamilan trimester kedua (14-28 minggu) satu kali kunjungan dan kehamilan trimester ketiga (28-36 minggu dan sesudah minggu ke-36) dua kali kunjungan (Saifuddin, 2005).

Hasil penelitian ini sejalan dengan penelitian yang dilakukan oleh Kusumo dan Yulian (2015) yang menyatakan bahwa terdapat hubungan antara tingkat pengetahuan ibu hamil dengan kepatuhan dalam melaksanakan kunjungan antenatal care di wilayah kerja Puskesmas Kartasura dengan nilaipvalue 0.044 sehingga $\mathrm{H}_{0}$ ditolak dan $\mathrm{H}_{a}$ diterima. Hal ini juga sejalan dengan penelitian yang dilakukan oleh Purboningsih (2014) yang juga menyatakan bahwa terdapat hubungan antara pengetahuan ibu hamil tentang ANC terhadap perilaku kunjungan ANC diketahui hasil perhitungan analisis Chi-square dengan nilai $p=0.008$ dimana pengetahuan ibu hamil tentang ANC memiliki hubungan yang signifikan dengan perilaku kunjungan ANC.

Berdasarkan hasil, teori dan penelitian terkait maka peneliti berpendapat bahwa tingkat pengetahuan ibu hamil sangat berpengaruh bagi kesehatan ibu hamil dan bayi, karena jika terdapat tanda-tanda bahaya pada ibu maupun pada janin ibu akan mengerahuinya, danibu akan mengkonsultasikan pada tenaga kesehatan baik itu bidan maupun dokter.Berdasarkan hasil teori terkait maka peneliti berpendapat bahwa dengan melakukan pemeriksaan kehamilan dari awal akan lebih mudah mengetahui perkembangan bayi. Seperti melakukan Kunjungan Antenatal Care (ANC) dengan rutin minimal 1 kali pada trimester I usia kehamilan 1-12 minggu, minimal 1 kali pada trimester II usia kehamilan 13-24 minggu, dan minimal 2 kali pada trimester III usia kehamilan $>24$ minggu, serta mendapat kan imunisasi TT pada ibu hamil.

\section{SIMPULAN}

Ada hubungan tingkat pengetahuan ibu hamil tentang ANC dengan kunjungan ANC di Puskesmas Kenten Laut Banyuasin Tahun 2020 dengan $p$ value $0,008<0,005$.

\section{SARAN}

Diharapkan untuk peneliti selanjutnya untuk melakukan penelitian tentang antenatal care dengan variabel yang lebih menarik sehingga bisa dikaji lebih banyak lagi tentang pemeriksaan antenatal care dan bisa dikaji ulang tentang permasalahan yang ada pada ibu hamil supaya ibu hamil lebih sehat dan berkualitas 


\section{Desi Hariani, Elvina Indah Syafriani}

\section{DAFTAR PUSTAKA}

Arikunto S. (2010). Prosedur Penelitian Suatu Pendekatan Praktik. Jakarta: Rineka Cipta., 10-13

Asrina,dkk .(2010) Asuhan kebidana masa kehamilan, Yogyakarta: Graha IImu

Depkes. (2002). Petunjuk Pelaksanaan Penetapan IndikatorMenuju Indonesia Sehat 2010. Jakarta: Depkes RI

Depkes RI. (2004). Asuhan Persalinan Normal. Jakarta: Depkes RI.

Dinas Kesehatan.(2017). Profil Kesehatan Provinsi Sumatera Selatan

Dinas Kesehatan.(2015). Profil Kesehatan Kota Palembang

Henderson, C., jones K. (2006). Buku Ajar Konsep Kebidanan. Jakarta: ECG.

Hidayat, AA. (2008). Metode Penelitian Keperawatan Dan Teknik Analisis Data.

Hutahaean, S. (2013). Perawatan Antenatal. Jakarta: Salemba Medika.

lliza, P.(2015) Gambaran pengetahuan ibu hamil tentang kunjungan pemeriksaan kehamilan di BPM Maliah Palembang . Jurnal. STIKES Mitra Adiguna Palembang.

Kemenkes RI. 2012. Survei Demografi dan Kesehatan Indonesia. Jakarta: Kemenkes RI.

Kusmiyati, Y. (2010) Penuntun praktium asuhan kehamilan, Yogyakarta : Fitra maya

Maliah (2017). Profil kesehatan Palembang Tahun 2017.
Maulana,M. 2008, Buku pegangan ibu panduan kehamilan lengkap

Manuaba, IBG.(2006). IImu Kebidanan, Penyakit Kandungan dan Keluarga Berencana Untuk Pendidikan Bidan. Jakarta: EGC.

Marni,2011. Asuhan kebidanan pada masa antenatal. Yogyakarta.Pustaka Pelajar

Notoatmodjo,S (2007) Metodologi penelitian kesehatan. Jakarta: Renika Cipta

Prawirohardjo, S.(2008). Buku Acuan Nasional Pelayanan Kesehatan Maternal dan Neonatal. Jakarta: PT. BPSP.

(2010). Buku Acuan Nasional Pelayanan Kesehatan Maternal dan Neonatal. Jakarta: PT. BPSP.

(2012). Buku Acuan Nasional Pelayanan Kesehatan Maternal dan Neonatal. Jakarta: PT. BPSP.

Pudiastuti. (2012). Asuhan Kebidanan Pada Hamil Normal dan Patologi. Yogyakarta: Nuha Medika.

Pusdiknakes.(2009). Asuhan Antenatal. Buku dua, Pusdinakes-WHO-JHPIEGO.

Saifudin, AB.(2008) Buku Acuan Nasional Pelayanan Kesehatan Maternal dan Neonatal. Jakarta : Yayasan Bina Pustaka Sarwono.

Sari.(2015). Hubungan Umur dan Pendidikan Ibu primigravida dengan Kepatuhan Kunjungan ANC. Jurnal: STIKES Budi Mulia Palembang.

Suryandari. (2013). Gambaran pengetahuan ibu hamil tentang kunjungan pemeriksaan kehamilan (antenatal care). Jurnal STIKES 'Aisyiyah Palembang 